\title{
RÁDIO: HISTÓRIA E ABRANGÊNCIA NA ERA DIGITAL ${ }^{1}$
}

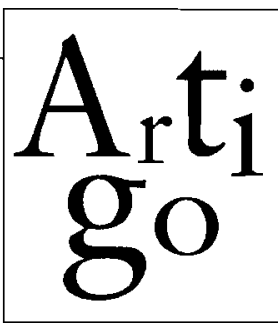

internacional

\section{O rádio continua sendo um dos mais abrangentes, populares e acessíveis meios de comunicação. Da válvula ao digital, o desenvolvimento tecnológico permite assegurar a ampliação de sua utilidade}

Temos sido negligentes, durante os últimos anos, ao deixarmos de dedicar atenção suficiente a um dos mais importantes meios de comunicação de massa: o rádio².

Um dos motivos por termos negligenciado o rádio pode ser explicado com base em uma relativa ausência de pesquisa publicada sobre esse meio, além da pequena prioridade que parece ser atribuída a ele em muitos departamentos de comunicação universitários. O glamour da televisão e do cinema parecem atrair o interesse de mais estudantes do que as ofertas mais rítmicas da música e da fala, às quais o rádio está limitado.

As dificuldades para se realizar pesquisas também são atribuídas à característica efêmera, transitória da programação de rádio, comparada aos jornais diários, sempre disponíveis para estudo, pois estão convenientemente guardados em hemerotecas. O adágio latino "verba fluunt, scripta manent" - "palavras [faladas] fluem e vão embora, a escrita permanece" - ainda descreve o problema de acesso aos dados relacionados ao rádio, comparado à pesquisa feita com jornais.
Gareth Price menciona o curto período de existência do rádio, o que, de alguma forma, torna-o menos atraente do que os jornais, consagrados por dois ou mais séculos de desenvolvimento, e sua falta de "apelo entre os jovens, mais atraídos por imagens visuais em um mundo cada vez mais multimídia"3. Mas ele enfatiza que o rádio "continua a manter as maiores audiências entre todas as mídias, e que tem feito parte dos acontecimentos políticos mais dramáticos ocorridos durante os últimos cinqüenta anos"'.

\section{HISTÓRIA: EVOLUÇÃOTECNOLÓGICA}

Antes de 1830, toda a comunicação dependia do contato imediato - de um remetente que enviava, através de mensageiro, um texto ou uma declaração oral a um determinado

\section{O AUTOR}

William E. Biernatzki, SJ

Editor de Communication Research Trends.

1. Comunicação \& Educação publica, com exclusividade em língua portuguesa, artigo de Communication Research Trends, v. 17. n. 4, 1997, cujo título no original é Radio.

2. Esta é a primeira edição de Communication Research Trends, em 17 volumes, totalmente devotada à pesquisa nesse meio. 3. PRICE, Gareth. The second half century (1945-1995): a continuing struggle for acess to the airwaves. (A segunda metade do século (1945-1995): uma luta contínua pelo acesso aos lobos do ar.) Unesco Courier. (Correio da Unesco.) fev, 1997. p. 22. 4. PRICE, G. The second... op. cit. 
receptor ou destinatário - ou de um sistema de sinais limitado pela distância, indo tão longe quanto pudessem ser vistos ou ouvidos diretamente. O telégrafo começou a mudar isso. Fios passaram a transportar mensagens codificadas, por centenas de quilômetros, em segundos. Stephen Lax descreve a história subseqüente das alterações na tecnologia de comunicação, além de explicar os princípios básicos sobre como funciona cada tecnologia. $\mathrm{O}$ rádio forma um ramo importante nessa árvore de evolução tecnológica.

Os telefones foram considerados, inicialmente, como instrumentos comerciais e não como dispositivos para fala social, ou para uso de pessoas comuns ${ }^{5}$. Com o passar do tempo, as redes de telefone foram estendidas de modo a incluir, gradativamente, os lares de pessoas de classe média; enquanto, em países em desenvolvimento, os pobres ainda não foram alcançados por ele de um modo significativo. A exigência de que haja serviço universal continua problemática na era digital, como demonstra o debate em relação à Lei de Telecomunicações dos Estados Unidos, datada de 1996 (Federal Communications Law Journal, 1997).

No início, o rádio sofreu com uma atitude semelhante - como um instrumento de uso para a navegação, de uso militar, diplomático e comercial - mas sempre prendeu o interesse de aficionados. As transmissões feitas para a recepção pelo público em geral iniciaram-se em 1920, nos Estados Unidos, e em 1922, na Grã-Bretanha. ${ }^{6 *}$

Em 1991, a Unesco informou que havia mais de 2 bilhões de aparelhos receptores em uso em todo o mundo, em contraste com ape- nas 831 milhões de aparelhos de TV e 540 milhões de linhas de telefone. O rádio, portanto, tornou-se um meio de massa por excelência, mas ele tem passado por muitas mudanças em suas formas de uso e, com a digitalização, está prestes a sofrer alterações técnicas significativas, que terão vastas implicações em seus usos social e cultural.

A transição do rádio, das válvulas aos transistores e daí aos circuitos integrados, permitiu a miniaturização e a maior durabilidade do equipamento. Comparado com as válvulas, tubos de vidro de baixa pressão contendo um pequeno elemento de aquecimento, os transistores eram pequenos, não esquentavam muito, não consumiam muita energia elétrica e não eram frágeis. Eles eram, portanto, ideais para equipamento portátil, operado à bateria. Vieram substituir as válvulas em quase todas as suas aplicações, exceto em sistemas que utilizam frequiências muito altas ou alta energia ${ }^{7}$.

O circuito integrado, melhor conhecido como chip de silício, usava refinamentos da mesma tecnologia utilizada em transistores, de modo a juntar muitos componentes eletrônicos em uma minúscula peça de silício. Isto resultou em maior confiabilidade, bem como na redução do tamanho de todos os tipos de equipamentos eletrônicos, inclusive dos rádios. Um dos efeitos mais significativos do circuito integrado no rádio foi a mudança da popularidade das transmissões de AM para FM. A história inicial do rádio dependeu mais das transmissões em AM (Amplitude Modulada de $5500 \mathrm{a} 1600 \mathrm{Khz}$ ) por causa da maior complexidade e dos custos dos circuitos de FM. Mas os chips reduziram muito o custo das trans-

\footnotetext{
5. LAX, Stephen. Beyond the horizon: communications technologies. Past. Present and Future (Além do horizonte: tecnologias de comunicação. Passado, Presente e Futuro.) Luton, UK: John Libbey Media/ University of Luton Press, 1997.

6. LAX, S. Beyond the... op. cit. p. 24.

* No Brasil a primeira transmissão radiofônica se deu em comemoração ao centenário da Independência (1922), transmitindo o Discurso do então Presidente da República Epitácio Pessoa. Depois somente volta a transmitir em 1923, quando Roquete Pinto lança a rádio Sociedade Rio de Janeiro. Em 1936, inaugura-se a Rádio Nacional que. durante 20 anos, representará a era de ouro do rádio brasileiro. (N. Ed.)

7. L.AX, S. Beyond the... op. cit. p. 27.
} 
missões em FM (Freqüência Modulada na faixa de 88 a $108 \mathrm{Mhz}$ ) e deram a ela uma vantagem, apesar de seu alcance limitado ${ }^{8}$.

No início da década de 70 , dá-se um passo adiante com o microprocessador: um circuito digital integrado avançado, cujo vasto número de componentes pode ser programado. Este desenvolvimento revolucionou a evolução de quase tudo o que opera com base na eletricidade. Muito desse potencial para mudar tanto o rádio como a televisão ainda estaria por surgir com a revolução digital.

\section{DESAFIO CRESCENTE: REVOLUÇÃO DIGITAL}

Lax reporta-se a Louis Rossetto na primeira edição britânica da revista Wired, escrevendo que a revolução digital poderia causar alterações sociais tão profundas que seu único paralelo provavelmente seria a descoberta do fogo. Lax comenta que essa grande afirmação e outras semelhantes estão sendo feitas para uma tecnologia que vem sendo desenvolvida há meio século e cuja característica principal é "o processo de conversão de analógica a digital, conhecido como modulação de código de pulso"".

$\mathrm{Na}$ natureza, ondas eletromagnéticas como som e luz são capazes de transportar sinais informativos, pois podem variar tanto em freqüência quanto em amplitude. Sua variação, em um sistema de comunicação, é análogo às variações nos materiais de instrumentação do sistema - por exemplo, as partículas de carbono em um telefone ou em um microfone. Os sinais digitais depen- dem de um simples chaveamento liga/desliga. Eles não variam através de uma faixa de possíveis valores como acontece com os sinais analógicos que transportam sua mensagem através de alguma combinação de ligado e desligado, seja qual for o meio em que serão transmitidos. A complexidade pode ser introduzida nos sinais ao aumentar os números de chaves liga/desliga e trabalhar com elas em diversas combinações. Lax usa o exemplo de uma sala onde há uma lâmpada com uma chave liga/desliga e uma sala onde há muitas de tais lâmpadas e chaves. A sala com uma só lâmpada e com uma só chave está escura ou clara, mas a sala com muitas lâmpadas pode ser iluminada de diferentes formas ao variar os números de lâmpadas que estão acesas/ apagadas em um dado momento ${ }^{10}$.

As vantagens da transmissão digital em relação à analógica são listadas por Lax como sendo: eliminação do ruído através do chaveamento liga/desliga do sistema digital; velocidade do processamento das informações; reprodução fiel (com o resultado da eliminação do ruído) e facilidade da interface e do processamento (em particular para a correção dos erros e criptografia para manutenção da segurança) da tecnologia de comunicação digital com a tecnologia do computador ${ }^{11}$. Uma limitação tem sido a grande quantidade de dados e a conseqüente ampla banda necessária para a transmissão digital (cinco a dez vezes maior do que a necessária para FM). No entanto, técnicas eficientes de compactação já foram desenvolvidas para solucionar esse problema e permitir a existência de mais canais em uma largura de banda equivalente ${ }^{12}$. 


\section{Impacto atual da digitalização no rádio}

O processo de mudança de transmissões analógicas para digitais já transmitiu ondas de choque por toda a indústria do rádio. Há dez anos era impossível se pensar em vender estações de AM nos Estados Unidos, pois mais da metade de todas elas afirmaram ter sofrido prejuízo em 1991. Não obstante esse fato, as estações AM agora estão sendo compradas por preços muito inflacionados. Um exemplo, escolhido aleatoriamente, é a KIEV-AM. Essa emissora, que transmite com uma potência de 15 quilowatts durante o dia e de um quilowatt à noite, para as cidades de Glendale e Los Angeles, Califórnia, foi vendida recentemente por 33,4 milhões de dólares, o preço mais alto jamais pago por uma estação de rádio $A M$ na área de Los Angeles.

Hoje, os compradores das rádios AM tendem a estar interessados na largura do espectro eletromagnético controlado por cada estação e, é claro, na audiência em potencial, pois a conversão das estações à tecnologia digital dará a essas emissoras clareza ainda maior do que a das FM. Além do mais, a possibilidade de fazer a interface dos sistemas digitais com computadores traz grandes promessas para possibilidades de desenvolvimento que, praticamente, ainda nem foram imaginadas.

Uma rádio totalmente digitalizada tornaria cada estação uma estação de canal claro - como é o caso da digitalização completa da indústria de televisão -, mas cada estação teria de comprar equipamento completamente novo. Todos os aparelhos receptores analógicos teriam de ser substituídos por receptores digitais ou ter conectados a eles um conversor que mudasse o sinal digital para um sinal analógico aceitável aos receptores analógicos. $\mathrm{O}$ custo de tal conversão maciça seria tão alto - e sem dúvida encontraria oposição significativa por parte dos consumidores - que projetar um período de tempo para a digitalização completa é altamente problemático. Apesar disso, o U.S. Federal Communication Commission (FCC, ou Comissão Federal de Comunicaçôes dos EUA) tentou projetar um prazo segundo o qual toda a indústria de rádio e também a de televisão estariam digitalizadas antes do ano 2010. A meta para o estabelecimento da televisão totalmente digitalizada anunciado pela FCC é o ano 2006, mas poucos acreditam que o objetivo possa ser alcançado ${ }^{13}$.

No Reino Unido, a pendente revolução digital foi tomada como um grande estímulo para se sancionar a Lei de Transmissão (Broadcasting Act) de 1996. Isso porque sentiu-se que as iniciativas britânicas na digitalização colocariam aquele país à frente do resto do mundo nessa tecnologia. Jeremy Landau expressou um pouco de cautela em relação a isso: "se a lei de 1996 cumprirá com a tarefa de tornar o Reino Unido um líder global nas transmissões digitais, isso ainda está por ser visto. Muito dependerá da viabilidade financeira da televisão digital, o que no presente é incerto"14.

Annelise Berendt, ao discutir o lado do consumidor de transmissões digitais de áudio (Digital Audio Broadcasting, DAB), diz que a $B B C$ espera que $40 \%$ dos lares do Reino Unido tenham um aparelho receptor DAB dentro de dez anos. Os primeiros aparelhos receptores comerciais foram apresentados na feira comer-

13. BROWN, Les. Digital terrestrial TV. Part l - An international survey. (TV digital terrestre: Parte 1: Uma pesquisa internacional.) InterMedia Special Report. v. 25, n. 2, 1997. p. 8.

14. LANDAU, Jeremy. The future regulation of broadcasting and telecommunications in the United Kingdom. (A futura regulamentação das transmissões de telecomunicações no Reino Unido.) Communications Law. v. 3, n. 1, 1998. p. 2. 
cial de Berlim, no verão de 1997, e esperava-se que os sinais de transmissão digital estivessem acessíveis a uma área da Europa ocupada por 100 milhões de pessoas até o final dacuuele ano, embora apenas uma pequena parcela desse número de pessoas já tivessem lais receplores. Parece que o elevado custo continua sendo um tator impeditivo para suá expansão.

\section{Substituiç̃o digital das ondas curtas}

As rransmissões de rádio digital - bem como de televisão digital, Televisão de Alta Definição (High Definition Television, HDTV), ou de qualquer outra nova tecnologia de comunicação - exigirão acordos sobre os padrões para que possam ser introduzidas de uma forma comercialmente viável, A corrida para a padronização digital está causando uma grande atividade mundial por parte dos interessados. Exemplo representalivo foi a reunião realizada em Guangzhou, na Chína, no início de 1998, na clual vinte das mais importantes organizações inundiais relacionadas à radiotransmissão assinaram um acordo para formar a Digital Radio Mondiale (DRM), É um consórcio para desenvolver especificações para a tecnologia digital a ser adotada para sistemas mundiais de transmissão direta por satélite e que seria capaz de substituir serviços ınundiais de ondas curtas ${ }^{15}$. A reunião de Guangzhou foi o resultado de um processo iniciado pela $B B C$ em um simpósio de radiodifusores internacionais que aconteceu em Londres, em 1994.

Fritz Groothues, ao discutir o mesmo consórcio, diz que na época em que foram iniciadas as discussões sobre isso já havia acordo sobre dois aspectos: que tal sistema mundial deveria ser digital e ser discribuído via satélite ${ }^{1 \text { is. }}$
Wijemanne descreve o objelívo do consórcio como sendo o de "produzir um sistema que servirá como um padrão mundial de transmissão digital único, testado, sem proprietário, direcionado pelo mercado e orientado pelo consumidor"17. Um importante objetivo desse esforço é o de persuadir aqueles que desenvolvem tecnologia digital para negociar suas diferenças e evitar competiçāo mutuamente danosa. Várias organizações estão desenvolvendo sistemas digitais para melhorar as transmussões nas faixas

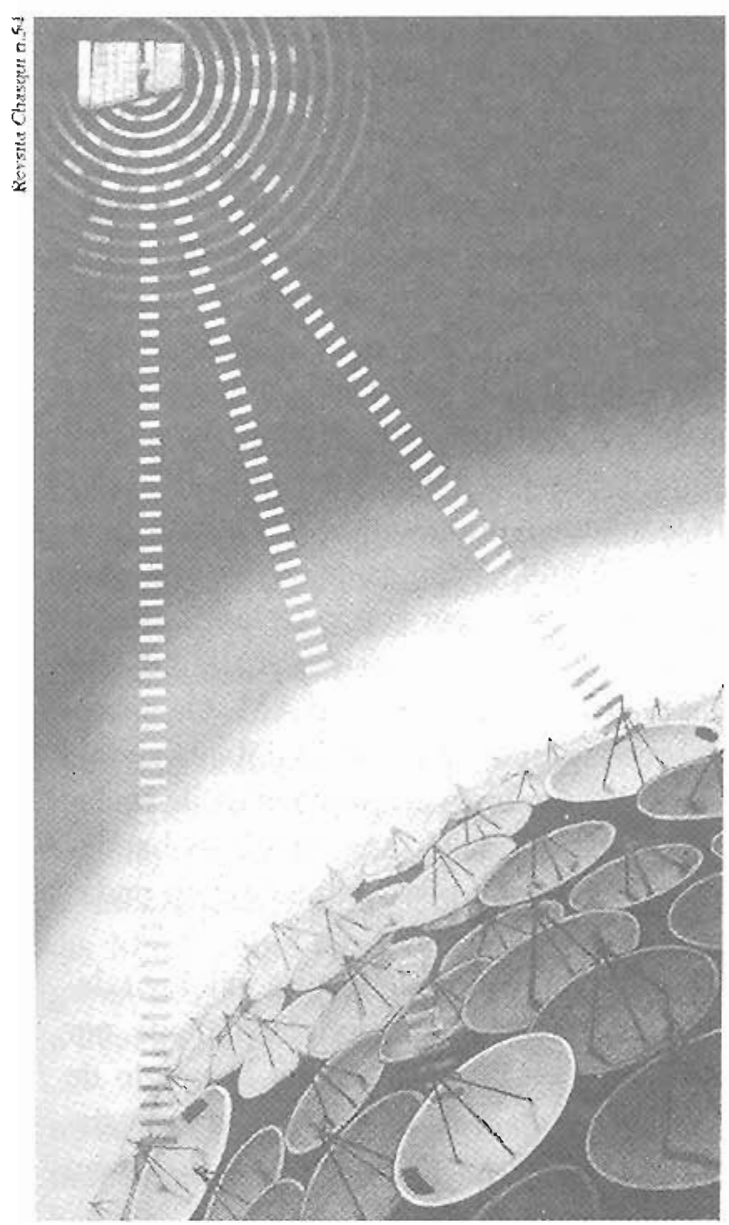

15. WIJEMANNE, Ruknin. Digima radis on irs, way' as beceming a realify. (Ráclio digital caminhando para se tornal uma realidade.) ABU News: News inagazıne of the Asia-Pacific Broadsessting Union, v. 17, n. 2. 1998, p. 5.

16. GROOTHUES, Fritz. The fursere of radio international services and the search for a global system. (O fuluro do rádlio: serviços incenacionais e a buscra para un siscema global.) InterMledia. v. 25. n. 4. 1997. p. 6.

17. WIJEMANNE. R. Diginal radis... op. cil. p. 6. 
AM e há, neste momento, pelo menos três sistemas que atingiram algum grau de desenvolvimento com êxito. Um deles é o da JPL/VOA (EUA), outro é o de Thomcast (França), enquanto o terceiro é da Deutsche Telekom (Alemanha).

Espera-se que o nível de colaboração seja maior entre aqueles que desenvolvem essa tecnologia do que o observado no caso da TV de Alta Definição (HDTV) ou depois com a TV digital. Espera-se também que a concorrência e os atrasos excessivos possam ser evitados. "Todos os sistemas têm características que estão em sintonia com as exigências do projeto. A tarefa da Mondiale é desenvolver um padrão mundial exclusivo para uma alternativa digital de transmissão em AF (Alta Frequiência), incorporando os melhores elementos dos sistemas"18.

Se o projeto proceder harmoniosamente e se for adotado um padrão mundial, "a transmissão digital nas bandas abaixo de $30 \mathrm{MHz}$ será inaugurada oficialmente. De acordo com o grupo Mondiale, depois de os protótipos de receptor e transmissor serem testados, dentro de três a cinco anos, a transmissão digital deve começar nas bandas de rádio AM. Os aparelhos, que custarão cerca de 30 dólares a mais do que os receptores convencionais de ondas curtas, serão modelos AM de várias bandas com meio digital e possivelmente com ondas longas e ondas curtas"19.

Em empreendimento comercial paralelo, um consórcio formado, principalmente, por investidores do Oriente Médio, chamado de WorldSpace Inc., está desenvolvendo um sistema de rádio digital de transmissão direta em
75 canais, transmitindo a partir de três satélites lançados em 1998 e 1999. A empresa espera obter muito de seu lucro com as vendas de um aparelho receptor a ser manufaturado por quatro grandes fabricantes japoneses.

Annelise Berendt é menos otimista sobre o potencial acordo entre os sistemas concorrentes. Por exemplo, o sistema conjunto europeu Eureka 147, inicialmente favorecido pela $B B C$, tem sido menos favorecido nos Estados Unidos, pois ele "busca fornecer uma transição sem atrito do sistema analógico para o digital, enquanto protege investimentos em redes existentes de FM e de $\mathrm{AM}^{\prime 20}$. O U. S. National Association of Broadcasters (Associação Nacional de Radiodifusores dos EUA) se opõe ao Eureka "com base na falta de uma nova freqüência, por causa do custo de novas redes e devido às preocupações de que ele possa introduzir nova concorrência" ${ }^{21}$. Além disso, as transmissões digitais de áudio, de modo geral, não têm três coisas que a televisão digital e a Internet têm: "uma tecnologia disponível para recepção, uma demanda provada de consumo, além de fornecedores de conteúdo, dispostos a investir na criação de produtos feitos sob medida para elas" ${ }^{22}$.

Aparelhos receptores, como os que acabam de ser descritos, podem ser necessários, pois as transmissões em FM e em ondas curtas, em sua forma analógica atual, ainda podem ser consideradas úteis o suficiente para serem mantidas. Donald MacFarland mudou de idéia, entre a primeira (1990) e a segunda (1997) edições de seu livro, que tratava do impacto da digitalização da rádio FM nos Estados Unidos.

Uma pesquisa informal realizada entre compradores de compact disk (CD) sugeriu a

18. BRINKLEY, Joel. Defining vision: the battle for the future of television. (Visão elucidativa: a batalha pelo futuro da televisão). Nova York: Harcourt Brace, 1997. 
ele que "boa fidelidade, ausência de barulho e distorção não estavam no primeiro lugar entre os motivos que tornavam os CDs importantes para esses consumidores. As pessoas demonstraram-se mais interessadas na habilidade de poder programar trilhas selecionadas, no fato de ser menos provável que os discos fossem danificados através de mau uso do que os cassetes ou os LPs, e da facilidade de armazenamento"23.

O autor aplicou a análise ao rádio, observando que, entre as duas edições de seu livro, "ficou demonstrada a eficácia de um sistema que poderá permitir a transmissão de áudio digital nas mesmas bandas que os radiodifusores hoje usam para seu serviço analógico". A partir dessa evidência, ele expressou sua mudança de opinião sobre a FM. "Ao contrário do que disse na primeira edição, estações analógicas de FM podem existir por muito tempo ainda. Contudo, a maioria das estações de AM terá todos os motivos para mudar para digital, pois isso oferecerá a elas a possibilidade de aumentar as parcelas de audiência em vez de continuar vendo-as em erosão. Por outro lado, as FMs de sucesso encontrarão muitos motivos para manter seu sinal analógico. À medida que as antigas AMs, orientadas pela programação falada, converterem-se ao digital e começarem a colocar no ar música de alta fidelidade, poderemos ver mais FMs convertendo-se à categoria de notícias/programas falados. A FM pode ser o canal perfeito para a voz humana (é o que algumas pessoas da indústria têm dito - esperançosamente - sobre a AM). A voz humana não demanda a mesma banda dinâmica nem a resposta de freqüência que a música. As vozes podem parecer muito naturais em FM". ${ }^{24}$
MacFarland cita o grande interesse comercial existente, e que é mais viável com a rádio de programação falada, em contraste com a rádio de programação musical, como um fator encorajador à adoção do formato de rádio de programação falada pelas estações de FM.

A rádio de programação falada tem mais tempo de propaganda que pode ser vendida e, portanto, maior potencial de lucro do que a rádio de programação musical, afirma MacFarland.

Berendt concorda com o ponto de vista de MacFarland de que as pessoas podem não ser atraídas à transmissão de áudio digital (DAB) apenas por causa de sua clareza. Uma atração mais provável para os compradores pode ser encontrada na portabilidade do DAB e em sua habilidade de distribuir dados. Como ele é sem fio e de uso mais claro e estável, o DAB é considerado uma melhoria sensível quando comparado aos sistemas analógicos para rádios de carros ${ }^{25}$.

\section{Novas tecnologias: novos papéis para o rádio}

Inovações em outras tecnologias também têm trazido mudanças nas formas como o rádio é usado e em seu papel na sociedade. MacFarland descreveu a história de alguma dessas mudanças que ocorrem desde a década de $60^{26}$.

A televisão, por exemplo, provocou no rádio tanto o primeiro quanto também o mais maciço impacto de todas as novas tecnologias. Nas décadas de 30 e de 40 , o rádio ser-

23. MACFARLAND, David. Future radio programming strategies: cultivating listenership in the digital age. (Estratégias para a programação do rádio no futuro: cultivando a audição de rádio na era digital). 2. ed. Mahwah, NJ/London: Lawrence Erlbaum Associates, 1997. p. 20.

24. MACFARLAND, D. Future... op. cit.

25. BERENDT, A. DAB... op. cit. p. 10.

26. MACFARLAND, D. Future... op. cit. 
viu como algo parecido, como a fogueira comunal da vila global, um papel que Marshall McLuhan $^{27}$ viu a televisão assumir e ampliar na década de 60 . No período inicial, as famílias sentavam-se ao redor de seus rádios, atentos ao som, mas tinham apenas uma caixa imutável para a qual olhar. A imagem em movimento da televisão rapidamente substituiu a função do rádio como a fogueira da família. O rádio teve, então, que se contentar em preencher os momentos nos quais assistir à televisão não era viável, em automóveis ou em situações de trabalho que exigem atenção visual - nos lares, escritórios, no campo, locais de construção, fábricas etc.

No início de 1998, os Estados Unidos tinham 12.276 estações de rádio e apenas 1.576 estações de televisão de transmissão terrestre. Mas estas estações de televisão eram suplementadas por outras 2.074 estações de poder muito baixo e por 11.600 sistemas de TV a cabo. O cabo penetrava em $66,1 \%$ dos cerca de 98 milhões de lares norteamericanos que tinham $\mathrm{TV}^{28}$. Os aparelhos de televisão muitas vezes ficam ligados o dia todo. No entanto, muitas vezes, na metade desse tempo ou mais, ninguém está presente na sala para assistir. Por outro lado, estimam-se que $77 \%$ dos americanos ouvem rádio todos os dias ${ }^{29}$.

\section{MTV, VCR, DBS e o cabo}

Segundo MacFarland, o agenda-setting ${ }^{30}$ (termo usado para designar a prática de o público pautar os seus temas e assuntos, baseado nos meios de comunicação) e as funções cultivadas pelos meios de comunicação de massa são alcançados com maior abrangência através do en- tretenimento do que através de notícias e de programação de atividades públicas ${ }^{31}$. Exemplo é a televisão musical (MTV). Ela é uma força cultural poderosa, criando "centenas de milhões de impressões sobre estilos de vida, valores sociais, problemas sociais e seus similares, vinculandose às nossas histórias pessoais em um nível de consciência próximo ao sonho"32. Embora as imagens coloridas e em movimento da $M T V$ tornem o meio mais poderoso para o entretenimento e para o condicionamento cultural, o rádio ainda tem uma função suplementar importante. "Ele também tem o papel de apoio à televisão na formação de opinião entre os adolescentes. Por causa de sua ubiqüidade, o rádio tem, por si mesmo, grande influência" ${ }^{33}$. O rádio continua dominante onde a portabilidade e a necessidade de lidar visualmente com outras atividades tornam impraticável assistir à TV.

Durante a década de 80 , outras tecnologias surgiram para interferir nas funções estabelecidas não apenas pelo rádio, mas também pelas transmissões de TV. $\mathrm{O}$ vídeo cassete (VCR) possibilitou a gravação e a decorrente interferência do telespectador nos horários da programação da $\mathrm{TV}$, bem como o aluguel de cassetes de filmes de grande sucesso. Mas o rádio conseguiu manter o seu valor e os seus ouvintes. Isto porque os telespectadores que dependem da recepção direta por satélite de modo geral recebem apenas notícias nacionais e internacionais daquela fonte, tornando-se dependentes novamente do rádio para obter as notícias locais e as previsões do tempo.

27. McLUHAN, Marshall. The Gutenberg Galaxy: the making of typographic man. (A galáxia de Gutenberg: o feitio do homem tipográfico). Toronto: University of Toronto Press, 1962. . Understanding media. (Entendendo a mídia.) Toronto: McGraw Hill, 1964.

28. B \& C. Broadcasting Stations. Broadcasting and cable. (Estações radiotransmissoras. Radiotransmissão e cabo.) Maio, 1998. p. 82. 29. B \& C. Radio beats. TV during day. Broadcasting and cable. (Derrota do rádio. TV durante o dia. Radiotransmissão e cabo.) Maio, 1998. p. 117.

30. Sobre agenda-setting ver: BARROS FILHO, Clóvis. Agenda-setting e educação. Comunicação \& Educação. São Paulo: CCA-ECA-USP/ Moderna. n. 5, jan./abr. 1996. p. 27-33. (N. Ed.)

31. MACFARLAND, D. Future... op. cit. p. 23.

32. MACFARLAND, D. Future... op. cit. p. 23.

33. MACFARLAND, D. Future... op. cit. p. 23. 
A TV a cabo também aumentou sua dimensão local, mas por um custo extra de assinatura aos telespectadores. Martin Cave observou, em relação à televisão, que a "transmissão por cabo elimina as deficiências mais sérias causadas pela falta de alcance (pois, dependendo da infra-estrutura, o cabo poderia transmitir até mil canais digitais)"34.

\section{Computadores e multimídia}

$\mathrm{O}$ advento da digitalização abriu muitas possibilidades para a interação entre o rádio, a televisão e os sistemas de telefone, por um lado, e os sistemas de comunicação e de processamento de dados baseados no computador, por outro. Mas não existe previsão confiável nesta área. Michael Marien observou "que a arte de fazer previsão sobre tecnologia ainda está subdesenvolvida e pode muito bem estar piorando em vez de melhorar". Enquanto algumas previsões "são impulsionadas pelo entusiasmo e/ou auto-interesse, e por isso provavelmente sejam exageradas, (...) outros recentes desenvolvimentos de tecnologia da informação (notadamente as máquinas de fax e o explosivo crescimento da Internet) eram antecipados por poucos observadores" 35 .

Lax define multimídia como "a integração perfeita de dados, texto, imagens de todo tipo e som dentro de um único ambiente de informações digitais" ${ }^{36}$. Um computador multimídia conteria, dessa forma, alto-falantes, um acionador de CD-ROM, uma placa de som e possivelmente um acionador de vídeo. A rádio digital e a TV digital quase inevitavelmente seriam unidas, pelo menos nas versões mais caras de tais combinações.
A Internet é basicamente uma tecnologia de telefone, embora "até aqui a telefonia da Internet não tenha tido a qualidade, confiabilidade e a segurança para ser considerada comparável aos serviços convencionais de telefone" ${ }^{37}$.

Muito dessa deficiência deve-se às trocas de pacotes - com grandes acúmulos de dados enviados pelas rotas disponíveis em rápidas explosões -, que fazem muito para reduzir os custos da Internet, mas que limitam a distribuição em tempo real e a sequiência ordenada necessária para boas transmissões de rádio. Se tal empecilho tecnológico puder ser contornado, a Internet seria utilizável para a transmissão do mesmo material que o rádio. Portanto, poderia ser uma concorrente da transmissão por rádio ou, pelo menos, poderia ser um canal para a recepção de rádio de transmissão. Custos iniciais para o equipamento e para as conexões podem excluir indefinidamente aqueles que não têm renda adequada para vincular-se à Internet, mas os custos do dia-a-dia são relativamente baixos.

\section{ALTERAÇÕES DE FORMATO: RÁDIO DE PROGRAMAÇÃO FALADA ${ }^{38}$}

O formato de programação falada (toda a programação não musical) e de notícias através do rádio ganhou popularidade em anos recentes, pelo menos entre os ouvintes mais velhos, aumentando nos Estados Unidos em mais de 500 estações entre 1989 e 1993. É possível especular sobre os usos psicológicos

\footnotetext{
34. CAVE, Martin. Regulating digital television in a convergent world. Telecommunications Policy. (Regulamentando a televisão digital em um mundo convergente. Políticas de telecomunicação.) v. 21, n. 7, 1997. p. 586.

35. MARIEN, Michael. New communications technology: a survey of impacts and issues. Telecommunications Policy. (Novas tecnologias de comunicação: uma pesquisa de impactos e temas. Políticas de telecomunicações.) v. 20, n. 5, 1996. p. 376.

36. LAX, S. Beyond... op. cit. p. 85

37. FRIEDEN, Robert M. Can and should the selected papers from the 1996. Telecommunications Policy. (Direitos e deveres em artigos selecionados de 1996. Políticas de telecomunicações.) Research Conference. Mahwah, NJ: Lawrence Erlbaum Associates, 1996. p. 183-204. 38. Ver sobre o assunto: HUTCHBY, Ian. Confrontation talk: arguments. asymmetries and power on talk radio. (Discurso e enfrentamento: argumentos, assimetrias e poder no discurso do rádio.) Mahwah, NJ: Lawrence Erlbaum Associates. 1996.
} 
que o rádio de programação falada poderia ter, criando a ilusão de companhia para os solitários, ou para aqueles isolados em seus veículos presos em engarrafamentos. Parece ser verdade que o rádio, mais que qualquer outro meio de comunicação de massa, gera um certo sentido de intimidade com sua audiência. Além de que, nos Estados Unidos, rádios com programação falada parecem estar aumentando em popularidade mais do que em outras partes do mundo, como na Espanha e na Grã-Bretanha, por exemplo. Na América Latina, rádios de programação falada parecem estar vinculadas a algo como o conceito de jornalismo público. Os repórteres do povo ${ }^{39}$, voluntários das comunidades locais, que são treinados para fazerem reportagens para estações regionais, fornecem um sabor da terra de origem às notícias, ligando intimamente a estação de rádio às comunidades da área de audiência. As participações pelo telefone dão uma forma interativa à programação falada que é especialmente popular, criando um sentimento especial de relacionamento entre o anfitrião, a pessoa que fez a ligação e o ouvinte passivo.

\section{Fragmentação do mercado}

\section{e a programação para nichos}

O mercado de rádio, como o mercado de TV, começou a testemunhar uma fragmentação acelerada na década de 80 , dando surgimento à percepção, entre anunciantes, de que o verdadeiro marketing de massa era uma coisa do passado, e que agora o mercado fragmentava-se em nichos - definidos pelos interesses especiais de audiências menores e delineadas bem mais estreitamente-, transfor- mando-se na nova realidade. Esta tendência foi promovida pela ampla variedade de opções de entretenimento disponíveis e concorrentes ao rádio, de modo que o ouvinte moderno se transformou em um "cliente de acesso à demanda alguém acostumado a conseguir ouvir o que quer ouvir e quando quiser ouvir"40. Por consequiência, as estações de rádio têm tido a tendência de se especializar em categorias, particularmente, por dialeto, grupo de interesse e idade, agindo assim em um grau muito maior do que a televisão tem feito.

\section{Rádio de programação musical}

Apesar do crescimento em popularidade das rádios de programação noticiosa/falada, os diversos formatos de programação musical ainda dominam nos Estados Unidos. As programações musicais dos tipos adultas $e$ contemporâneas $(A C)$, rádio de sucessos contemporâneos (ou Contemporary Hit Radio, CHR), country, rock alternativo/novo e até mesmo dos anos dourados são populares, mas com muitos rivais, dependendo da região e das modas passageiras. Uma pesquisa contínua informou, no início de 1998, que as rádios com programações noticiosas/faladas, $A C$, country e $C H R$ continuam entre os formatos mais populares, mas isso varia muito por região ${ }^{41}$.

Rádios com programação falada podem atrair atenção mais concentrada dos ouvintes do que os formatos musicais menos exigentes. O rádio, como um todo, convida a participação mais intensa - pois todo seu estímulo vem através apenas de um dos sentidos - do que a televisão, que faz mais por seus telespectadores através dos dois sentidos, e assim exige menos

39. Em vários países da América Latina, principalmente Bolívia, Equador e Colômbia, há experiências importantes com as rádios populares. Instituições ligadas à Igreja Católica e a outras entidades ministram cursos rápidos para a preparação de repórteres e radialistas, preparando-os para que possam, a partir de sua própria comunidade, produzir noticiário para as rádios locais e nacionais. Ver mais sobre o assunto em: Revista Signo y Pensamiento. Radio. Bogota, Colómbia: Facultad de Comunicación y Lenguage, Pontificia Universidad Javeriana. n. 33, 2. sem. 1998. (N. Ed.)

40. MACFARLAND, D. Future... op. cit. p. 72-93.

41. B \& C. Radio beats. op. cil. p. 117. 
trabalho das imaginações de suas audiências. Marshall McLuhan ${ }^{42}$ classificou a televisão como um meio frio e o rádio como um meio quente. Segundo o autor, o rádio exige maior envolvimento de seus ouvintes, em contraste com o assistir passivo, tão freqüentemente característico de uma audiência de TV.

MacFarland acha que a estação de rádio que tem formato musical é, e continuará sendo, mais comum do que as que têm programação falada, pelo menos nos Estados Unidos, mas a televisão musical continua sendo mais atraente do que a música pelo rádio. Um estudo citado por MacFarland revelou que " $43 \%$ dos telespectadores adolescentes que hoje assistem à $M T V$ antes ouviam rádio, apesar de ainda considerarem que as rádios oferecem canções melhores e uma variedade musical maior"43.

Raymond L. Carroll e seus colaboradores enfatizam que os ouvintes são "membros de uma audiência em evolução, caracterizada pelo desenvolvimento psicológico, afiliação cultural e até mesmo pelo constante acesso às diferentes mídias, cujas opções se tornam mais acessíveis devido à sua maior renda; ou então caracterizadas como as mais desejáveis por causa da programação transmitida"'44.

Particularmente os usuários mais jovens podem usar dois ou três tipos de mídia de uma só vez, ouvindo música em rádio ou em $C D$ player, enquanto lêem um livro na presença de um aparelho de televisão, ligado com o som baixo, por exemplo. A atenção do receptor pode variar com a alteração do conteúdo, ou seja, o surgimento de um conteúdo interessante na tela da TV pode inspirar o indivíduo a baixar o volume do rádio e ignorar o livro; ou uma canção favorita que surja no rádio pode fazer o ouvinte abaixar o volume da TV e aumentar o volume do rádio, enquanto a leitura continua ${ }^{45}$.

\section{NECESSIDADE DE REGULAMENTAÇÃO}

Desde os primórdios do rádio, tornouse evidente que transmissões coerentes exigiriam que algum tipo de autoridade designasse as frequiências e garantisse que as rádios não infringiriam as faixas de frequiência de outras emissoras do espectro. A natureza do espectro eletromagnético é tal que diferentes segmentos dele são mais úteis para algumas funções do que para outras. Uma das primeiras prioridades nos esforços de regulamentação, portanto, foi decidir que freqüências deveriam ser usadas para quais atividades. Aeronaves e navios, por exemplo, precisariam usar frequiências capazes de atingir longas distâncias bem como comunicações locais. As transmissões internacionais têm funcionado melhor empregando as ondas curtas, enquanto as transmissões em AM funcionam melhor usando ondas de comprimento médio. As transmissões em FM e de televisão, por sua vez, precisam de frequiências mais altas.

$\mathrm{Na}$ Grã-Bretanha, e na maioria dos países onde as transmissões de mídia de massa foram vistas como prerrogativas, se não do Estado, pelo menos como um monopólio controlado pelo governo, o cumprimento da disciplina da definição das faixas de freqüência não

\footnotetext{
42. McLUHAN, M. Understanding media. op. cit.

43. MACFARLAND, D. op. cit. p. 17. MELTON, G., GALICIAN, M. A sociological approach to the pop music phenomenon: radio and music utilization for expectation, motivation and satisfaction. (Uma abordagem sociológica do fenômeno da música pop: utilização do rádio e da música como expectativa, motivação e satisfação.) Popular music and society. (Música popular e sociedade.) v. 11, n. 3,1987, p. 35-46.

44. CARROLL, Raymond et al. Meanings of radio to teenagers in a niche programming era. Jourmal of broadcasting and electronic media. (Sentidos do rádio para jovens na era da programação para nichos. Jomal de radiotransmissão e mídia eletrônica.) v. 37, n. 2 , 1993. p. 159-176.

45. Jesús Martín-Barbero fala sobre essa característica da juventude em entrevista exclusiva concedida a Comunicação \& Educação. n.15, maio/ago. 1999 , p. 62-80. (N. Ed.)
} 
parece ter criado um problema significativo exceto no caso de transmissões clandestinas. Em um ambiente de transmissão totalmente comercial, como é o dos Estados Unidos, o caos prevaleceu durante um período. De fato, havia tantas indicações desse caos que, em meados da década de 20 , uma autoridade dos correios britânicos, tendo observado essa situação, voltou à Grã-Bretanha dando ênfase à necessidade de haver forte controle para evitar a ocorrência de semelhante caos em seu país. A maioria dos radiodifusores norte-americanos reconheceu, a longo prazo, a necessidade de reciprocidade e cortesia para que o sistema funcionasse eficientemente para eles mesmos, bem como para os outros.

$\mathrm{Na}$ maioria dos países a regulamentação de transmissões tende a cair, assim como outras comunicações sob a autoridade do serviço postal. Geralmente se as transmissões não são mantidas sob o controle direto do governo, elas podem ser colocadas sob a responsabilidade de um monopólio servido pelo governo, como a $B B C$, na Grã-Bretanha, ou a $N H K$, no Japão. Na Grã-Bretanha e em outros lugares, esta situação foi complicada pelo surgimento de transmissões comerciais, o que exigiu uma estrutura administrativa paralela para lidar com realidades de funcionamento e estrutura muito diferentes.

\section{Estados Unidos}

Nos Estados Unidos, o sistema de transmissões começou totalmente comercial e independente. A regulamentação veio mais tarde e começou a ser realizada pelo Departamento de Comércio. Foi então estabelecida a Comissão Federal de Rádio dentro desse Departamento, com a tarefa de lidar com a crescente indústria da área. Por fim, em 1934, criou-se o Communications Act (Lei das Comunicações), que estabeleceu a Federal Communications Commission, FCC ou (Comissão Federal de Comunicações), como uma agência independente. William L. Fishman lembra que "o Congresso assumiu, ao escrever a Lei de 1934, que o espectro de freqüência de rádio pertencia ao governo federal"46. Essa opinião foi consolidada nos círculos oficiais, "mas a sua justificação não é auto-evidente".

O presidente da FCC, Reed Hundt, mantém a opinião de que "o espectro pertence ao povo: 'Aqueles que caracterizam as obrigações do interesse público como abusos dos direitos daqueles que têm as licenças, ignoram o fato de que os licenciados usam a preciosa propriedade pública para seu próprio ganho pessoal"47.

Em oposição a essa opinião há uma decisão do Tribunal Federal de Apelações que parece indicar que o espectro alocado é de fato posse dos licenciados privados e que o governo possui apenas aquilo que não foi alocado. Contudo, Fishman conclui: "O debate sobre a origem e a extensão dos direitos de propriedade do governo sobre o espectro de ondas de transmissão continua até hoje. É indiscutível, no entanto, que ao permitir que o bem público fosse utilizado como bem particular, o Congresso fosse cuidadoso em especificar que tal autorização é temporária, limitada e sujeita a ser retirada sob uma ampla variedade de circunstâncias" 48 .

Rosston e Steinberg dizem que "um dos

46. FISHMAN, William L. Property rights, reliance and retroactivity under the Communications Act of 1934 . (Direito de propriedade, confiança e retroatividade sob a Lei de Comunicaçōes de 1934.) Federal Communications Law Journal. v. 50, n. 1, 1997. p. 4.

47. FISHMAN, W. L. Property... op. cit. p. 5.

48. ROSSTON, Gregory L., STEINBERG, Jeffrey S. Using market- based spectrum policy to promote the public interest. (Política do espetro baseado no mercado para promoção do interesse público.) Federal Communications Law Journal. v. 50, n. 1, 1997. p. 88-89. 
principais motivos pelos quais o Congresso estabeleceu, há mais de 60 anos, a Comissão Federal de Comunicações foi para gerenciar o espectro de rádio para que o público pudesse receber o benefício máximo de seu uso"49. Antes de 1927, o secretário de comércio emitia licenças e designava as frequiências, mas os tribunais despachavam que ele "não tinha a autoridade para negar licenças com base no fato de que causariam interferência; nem mesmo limitar o poder dos licenciados, suas freqüências e nem as horas de operação" ${ }^{50}$. O resultado dessa decisão judicial, em 1924, foi a interferência progressiva de uma estação em outras, a ponto de o uso do espectro, por parte de todos, ficar prejudicado. A Lei do Rádio de 1927 respondeu a essa situação e a Lei das Comunicações de 1934 fortaleceu a autoridade e estabeleceu a FCC para administrá-la. Subseqüientemente, "a Comissão recebeu autoridade ampla, consistente com o interesse, conveniência e necessidade públicas, para licenciar usuários do espectro de rádio; impor condições aos licenciados; prescrever a natureza dos serviços a serem fornecidos pelas estações ou classes de estações; e evitar a interferência nos usos autorizados do espectro dos licenciados" ${ }^{51}$.

As alterações tecnológicas deixaram muitos dos princípios articulados pela $\mathrm{FCC}$, em 1945, obsoletos. A Comissão moveu-se, então, "na direção de um método mais harmonioso para a operação das forças de mercado" ${ }^{52}$. Uma dessas adaptações foi permitir que os fornecedores de serviços aumentassem a flexibilidade para responder às iniciativas do mercado para a produção de diversos serviços que os consumidores desejam e precisam ter. Além disso, a FCC pediu e recebeu "autoridade para dar licenças através da realização de concorrências de uma forma eficiente e baseada no mercado"s3. Isto é, os segmentos da frequiência das ondas de rádio deviam ser, dali para frente, leiloados para aquele que desse o lance mais alto.

\section{Muitos têm questionado essa desre-} gulamentação e venda das freqüências, afirmando que ela é uma alienação de um recurso natural valioso que passa ao controle de setores ricos e poderosos da sociedade. Os responsáveis negam essa possibilidade, dizendo que "o mandato controlador da Comissão é para promover o interesse público" e que "o uso por um licenciado da frequiência de rádio não constituirá a posse de tal espectro"s4. Eles continuam argumentando que "usuários privados devem usar o potencial da frequiência de forma a servir ao interesse público".

Mas acreditam que os usuários são melhor servidos ao permitir que as forças de mercado exerçam sua força, em vez de exigir o controle público que pode, a longo prazo, diminuir o bent-estar dos usuários, à medida que estaria impedindo que as forças de mercado operem de forma a vender os serviços mais desejados por um custo eficiente e preços competitivos" 55 .

Rosston c Steinberg relutantemente admitem que "sob algumas circunstâncias as forças de mercado deixarão de produzir resultados que maximizem o bem social" 56 ,
49. ROSSTON, G. L., STEINBERG, J. Using... op. cit. p. 89. 50. ROSSTON, G. L., STEINBERG, J. Using... op. cit. p. 89. 51. ROSSTON, G. L., STEINBERG, J. Using... op. cit. p. 89 52. ROSSTON, G. L., STEINBERG, J. Using... op. cit. p. 90. 53. ROSSTON, G. L., STEINBERG, J. Using... op. cit. p. 90. 54. ROSSTON, G. L., STEINBERG, J. Using ... op. cit. p. 91. 55. ROSSTON, G. L., STEINBERG, J. Using ... op. cit. p. 92. 56. ROSSTON, G. L., STEINBERG, J. Using... op. cit. p. 103. 
mas tendem a considerar isso como uma exceção em vez de uma regra.

\section{Grã-Bretanha}

Utilizar o princípio econômico do laissez faire ${ }^{57}$, manifestado por Rosston $\mathrm{e}$ Steinberg, seria visto com desalento por muitos na Europa, onde, como foi mencionado acima, a indústria de radiodifusão tem sido tipicamente centralizada desde seu início e apenas recentemente abrindo-se às transmissões independentes (o grifo é nosso) e comercializadas no padrão norte-americano.

$\mathrm{Na}$ Grã-Bretanha, o Independent Broadcasting Authority (IBA, ou Autoridade Independente de Transmissões) foi estabelecido na década de 50, quando a transmissão independente de televisão quebrou o monopólio da $B B C$. A rádio independente, iniciada em 1972, está limitada a estações locais. A $B B C$, além dos serviços nacionais, tem um total de 39 estações locais que competem com as mais de 170 estações privadas locais. No geral, o princípio das transmissões de serviço público na Grã-Bretanha vive sob a ameaça reconhecida do aumento da desregulamentação e comercialização. $\mathrm{O}$ mesmo se repete em outros países europeus com tradição de serviço público centralizado.

Prosser identifica "duas características chaves na regulamentação de transmissões no Reino Unido. A primeira é a ausência de qualquer prescrição legal detalhada (em contraste, digamos, com a França), e a outra é o uso de ação administrativa informal ou de acordos privados" ${ }^{\circ}$. Essa aparente informalidade disfarça um nível relativamente alto de controle regulatório exercido através da $B B C$, da IBA ITC e pela Autoridade do Rádio. Durante a década de 80 , segundo Prosser, as "novas tecnologias e o liberalismo econômico pressionaram para formas mais leves de regulamentação" ${ }^{\circ 9}$. Landau, mais recentemente, citou o House of Lords Select Committee (Comitê Seleto da Casa dos Lordes) sobre ciências e tecnologia, dizendo que "o verdadeiro teste de sucesso da diretriz do Reino Unido sobre comunicações deverá ser medido, muito provavelmente, pelos critérios de regulamentação leve e lógica"60.

Devido à acelerada digitalização $\mathrm{e}, \mathrm{em}$ parte, pela convergência de vários meios de comunicação, criou-se, em 1996, uma nova lei de radiodifusão no Reino Unido. Os objetivos da lei eram muito parecidos com os da legislação anterior, exceto pelo reconhecimento da iniciativa trazida pela iminente revolução digital: "Os objetivos básicos da Lei de 1996 foram proteger e encorajar a polaridade, diversidade e qualidade das transmissões dentro do Reino Unido, manter padrões de imparcialidade, gosto e decência; e encorajar a competição para permitir que o Reino Unido lidere o caminho à nova era digital"’l.

Landau vê a probabilidade de o novo quadro legal ser incapaz de acompanhar os rápidos desenvolvimentos tecnológicos. Ele afirma que "como aconteceu com a Lei de Radiodifusão de 1990, que rapidamente se tornou obsoleta, é provável que a Lei de 1996 sofra um destino semelhante. Alguns comentaristas defendem que mais legislação relativa às transmissões seja necessária dentro dos próximos cinco anos, devido ao desenvolvimento da tecnologia digital.

57. Expressão do liberalismo econômico, que significa deixar que as leis de mercado atuem livremente, ou seja, deixar que os interesses daqueles que atuam no mercado regulem os interesses do bem-estar público. (N. Ed.)

58. PROSSER, Tony. Public service broadcasting and deregulation in the UK. (Serviço público de transmissão e desregulamentação no Reino Unido.) European Journal of Communication.v. 7, n. 2, 1992. p. 173-193. 
Em 1988, o governo estabeleceu o Broadcasting Standards Council (Conselho de Padrões de Radiodifusão), com o objetivo de desenvolver um código de controle de como são retratados o sexo e a violência nos meios de comunicacão, especialmente na televisão, tornando-o permanente na Lei de Radiodifusão de 1990. Colin Shaw, diretor em final de mandato do Broadcasting Standards Council, observou, em 1996, a falta de popularidade do Conselho entre os responsáveis pelas transmissões: "nos últimos seis ou sete anos, disse ele, tive a tarefa de tornar o Broadcasting Standards Council, que era universalmente analisado, um pouco menos criticado e mesmo, em algumas ocasiões, fazêlo obter um ou dois momentos de respeito"62.

A Grã-Bretanha tem, "na atualidade, pelo menos 14 corpos de regulamentação que afirmam ter jurisdição sobre questões de mídia e telecomunicações". Um desses é a Independent Television Commission (ITC, ou Comissão Independente de Televisão), que também está encarregada das transmissões de rádio. Outro é o Oftel, criado pela Lei de Telecomunicações de 1984, que "regula licenças cedidas sob a Lei de 1984, as quais permitem que o licenciado instale e mantenha em funcionamento um sistema de telecomunicações através do qual podem ser fornecidos serviços de televisão e telecomunicações" jurisdição do ITC se estende à regulamentação dos sinais de telecomunicações enviados através de telégrafos sem fio, caso esses sinais sejam usados para transportar serviços de televisão ou de rádio. Além disso, o ITC é responsável pela regulamentação de serviços locais de distribuição, que são sinônimos de transmissões de televisão a cabo" ${ }^{64}$. Segundo o autor, as jurisdições dos organismos de regulamentação tendem a se sobrepor e, assim, é necessária a consolidação de todas as regulamentações sob um único órgão regulador.

\section{Países em desenvolvimento}

Embora os governos particularmente centralizados tenham aparentemente uma tendência natural de manter controle rígido sobre as transmissões e sobre todos os outros meios de comunicação, as realidades financeiras têm, em muitos casos, feito com que eles abram seus sistemas à propaganda e à concorrência comercial. $\mathrm{O}$ apoio de um governo ou de um sistema servido pelo governo, através de taxas de licença, provou ser impossível de funcionar na maioria das situações de Terceiro Mundo, bem como em muitos países desenvolvidos. A alternativa seria apoio direto por impostos, o que a maioria considera uma sobrecarga indesejável para os bolsos do cidadão. O resultado então, é o aumento na comercialização.

Durante a década de 30 , exportadores dos Estados Unidos à América Latina rapidamente reconheceram que a propaganda feita pelo rádio teria enorme potencial para aumentar suas vendas naquela região. Este fator aumentou a já existente forte pressão em favor de um sistema completamente comercial de transmissão de rádio, seguindo o padrão norte-americano. Esse padrão foi estendido à televisão, na medida em que ela foi se desenvolvendo, durante a década de 50 . A propaganda feita por corporações transnacionais continua sendo um fator importante no financiamento das estações de rádio e de televisão em toda a América Latina. 
Em muitos países as diferenças de idioma são fatores complicadores para o rádio e outros meios de comunicação de massa. A Papua Nova Guiné (PNG) é um exemplo bastante extremo. Esse país tem uma população de cerca de 4 milhões de pessoas que falam mais de 700 idiomas diferentes. Usam, entretanto, com certa frequiência, o pidgin (forma simplificada de fala, mistura de várias línguas) e o inglês para a comunicação entre os diferentes grupos étnicos. Seu terreno montanhoso dificulta as transmissões terrestres de rádio e de televisão. A televisão via satélite está disponível a partir de diversas fontes e é distribuída por cabo em locais onde o tamanho da população faz jus a isso. Toda a recepção é de TV internacional, de modo que nenhuma notícia nem mesmo fatores e características culturais domésticos aparecem. Por consequiência, o rádio é a principal fonte eletrônica de notícias e de informações locais relevantes. Antes da independência da Papua Nova Guiné as transmissões de rádio foram iniciadas pela Australian Broadcasting Company $(A B C)$ e assumida, em 1975, pela National Broadcasting Commission (NBC), que opera em 19 estações provinciais. A maioria dos programas da rede $N B C$ é feita em inglês, e alguns em pidgin. Os programas originados localmente são, de modo geral, produzidos em línguas dos vernáculos locais ou em pidgin.

\section{Regulamentação internacional}

As ondas eletromagnéticas obviamente não respeitam as fronteiras políticas. Por consequiência, o problema de as transmissões de um país interferirem com as de outros tem sido inerente às transmissões de rádio desde seus primórdios. Esforços internacionais para regulamentar as comunicações através de fron- teiras internacionais antecedem a existência do rádio, remetendo-nos à fundação da International Telegraphic Union, iniciada em 1865, para estabelecer regras e padrões para enviar mensagens telegrafadas de um país para outro. A palavra telefone foi adicionada ao seu nome no último quarto do século XIX. Uma organização separada foi estabelecida por 27 países, em 1906, para regulamentar a comunicação de rádio marítimo, e essa também assumiu a tarefa de definir padrões para o equipamento e tecnologia de rádio. Por fim, em 1932, as duas organizações uniram-se para formar a International Telecommunication Union (ITU ou União Internacional de Telecomunicações). Tal união tornou-se uma agência das Nações Unidas em 1947.

Dentro da ITU estão incorporados dois comitês consultores internacionais, um para telégrafos e telefones, outro para rádio, bem como para a Diretoria de Registro de Frequiência Internacional. A World Administrative Radio Conference (WARC, ou Conferência Mundial Administrativa de Rádio) da ITU reúne representantes de países interessados em definir a alocação de freqüências internacionais de rádio, bem como em negociar outras áreas de potencial conflito no uso das freqüências de rádio. Desde o início de 1980, uma conferência especial, a Space WARC, reúne-se periodicamente para estabelecer regras bem equacionadas para o uso de satélites por diversas nações. Ela foi solicitada pelos governos do Terceiro Mundo, que temiam sua inabilidade em desenvolver comunicação via satélite, o que para sempre os eliminariam de oportunidades iguais, comparados às nações tecnologicamente avançadas, para o uso futuro do número limitado de locais de transmissão geostática por satélite, em órbita ${ }^{65}$. 


\section{Reguladores Regionais}

Questões de uso de frequiências regionais parecem razoavelmente bem resolvidas no nível da ITU e da WARC. Mas muitas dúvidas permanecem, nas áreas de conteúdo e padrões de mídia, para a integração das muitas tecnologias que atualmente estão em concorrência e/ ou convergindo. Essas questões têm sido, talvez, as mais críticas, mas ao mesmo tempo têm sido confrontadas mais diretamente pela Comunidade Européia. Landau acha que também ela manifesta "uma clara necessidade do estabelecimento de uma nova estrutura para a regulamentação da mídia e das telecomunicações"

\section{RÁDIO E DEMOCRACIA: PIRATAS}

Embora a expressão rádio pirata, da forma como é usada no Leste Europeu, traga à mente imagens de radiodifusores operando a partir de navios enferrujados, ancorados imediatamente fora do limite de fronteira de 25 milhas e transmitindo rock-and-roll irreverente para adolescentes rebeldes, Tim McGuire ${ }^{67}$ demonstra que a transmissão e recepção clandestinas têm importante papel em muitos países onde a expressão política livre é suprimida. Citando Lawrence Soley e John Nichols ${ }^{68}$, McGuire observa a dificuldade que há para pesquisar este tópico, pois "estações clandestinas, de modo geral, emergem das sombras mais escuras do conflito político. Elas são frequientemente operadas por grupos revolucionários ou por agências de inteligência que são incapazes ou que não têm o desejo de deixar um registro documentário de suas atividades. $\mathrm{E}$, ao contrário da propaganda impressa, não deixam rastros" $"$.

Até hoje, transmissões clandestinas têm sido fáceis e baratas de efetuar. "Tudo o que é necessário é um transmissor e uma antena que podem custar menos de $\mathbf{3 0}$ dólares, além de uma fonte para entrada de áudio, como um toca-fitas, um CD ou microfone. Não é necessário qualquer conhecimento técnico especial" "770. Mas essas transmissões são muito perigosas, por vários motivos. A interferência com transmissões de aeronaves ou com ondas de emergência podem causar desastres fatais.

Além de causar perigo a outros, há a grande possibilidade de ser pego, pois a maioria dos países é sensível ao uso ilegal das ondas de transmissão. Na Grã-Bretanha, "171 estações piratas de rádio foram atacadas 842 vezes em 1996, demonstrando a determinação das autoridades e a tenacidade dos radiodifusores piratas" ${ }^{71}$.

Em contraste com as revoluções que fracassaram, o papel de uma rádio pirata, em revoluções que obtiveram êxito, pode ter sido o de interlocutora dos fatos. Por exemplo, durante a revolução popular nas Filipinas, contra a ditadura de Marcos, em 1986, um radiodifusor clandestino de baixa energia, operando nas freqüências de sua estação principal, que era religiosa, foi fundamental na convocação e coordenação dos movimentos dos manifestantes em Manila e

66. LANDAU, J. The future... op. cit. p. 2.

67. MCGUIRE, Tim. Will the pirates sunive in the age of new media? (Sobreviverão os piratas na era das novas mídias? InterMedia. v. $25, \mathrm{n}$. 4, 1997. p. 11-13. BROWN, Jo Langham. et. al. Tune in or buy in? Papers from the 27th University of Manchester broadcasting symposium. (Regular ou comprar? Comunicação ao $27^{\circ}$. Simpósio de radiodifusão.) Luton, UK: John Lisbey Media/ University of Luton Press, 1997 . p. 96. 68. SOLEY, Lawrence C., NICHOLS, John S. Clandestine radio broadcasting: a study of revolutionary and counter revolutionary electronic communication. (Rádio clandestino. Um estudo da revolucionária e contra-revolucionária comunicação eletrônica.) Nova York/Westport, CR/ Londres: Praeger, 1987.

69. MCGUIRE, T. Will... op. cit. p. 11.

70. MCGUIRE, T. Will... op. cit. p. 11.

71. MCGUIRE, T. Will... op. cit. p. 12. 
na transmissão de notícias essenciais. Mina Ramirez descreveu o processo da Revolução do poder do povo nas Filipinas como segue: "Nas Filipinas, tanto os meios de comunicação de massa como a mídia de grupo, uma comunicação face a face (que evoluiu durante 20 anos de opressão política), complementaram-se uns aos outros como elementos integrais de mudança social que levaram a uma vitória política em fevereiro de 1986. A Rádio Veritas instruiu o povo para trazer um rádio, reunir-se em pequenos grupos e refletir sobre aquilo que estavam compromissados a fazer. Essa foi, na prática, a mídia do grupo. Ao mesmo tempo, esta estação funcionou como um catalisador que amplificou e aumentou o processo de despertar. O povo das Filipinas que não estava em Manila permanecia, assim, envolvido ativamente, à medida que carregava seus rádios, de um lado para outro, rezando e expressando sua solidariedade com o processo de liberação política"’?2.

McGuire vê uma grande alteração acontecendo na rádio pirata política, devido ao crescimento da Internet. Esta última "reuniu milhares de grupos noticiosos que servem a muitos interesses. Na Internet, o conteúdo da rádio pirata de natureza radical e de oposição ao status quo é publicado livremente sem medo de ataques da polícia e do confisco do equipamento"73.

Ele cita Stephen Jones, estudante de ciências de computação envolvido com rádio pirata, que acredita que a Internet ajudará e não substituirá a rádio pirata, pelo menos no Reino Unido. Como fazer a propaganda de frequiências piratas e ilegais no rádio, na televisão e nos meios impressos? Sites da Internet são o único local onde radiodifusores piratas podem ser anunciados legalmente. McGuire especula que, longe de fazer o marketing do declínio da rádio pirata, a Internet pode impulsioná-la para o próximo século, unindo radiodifusores piratas em uma aliança global maleável que busca atender à demanda dessa pequena audiência.

A Internet, em várias combinações com o rádio, a imprensa, a televisão e outros meios, abriu amplas possibilidades para a comunicação revolucionária e subversiva sem inibições. Os usos criativos aos quais ela tem sido colocada pelos rebeldes zapatistas no México são um exemplo excepcional.

\section{Padrões revolucionários}

Nas revoluções do passado, o primeiro e principal objetivo das forças revolucionárias era o de capturar a sede do governo - o castelo, o palácio presidencial, ou pelo menos alguns dos símbolos da opressão governamental. Ao final do século XX, tal padrão mudou dramaticamente, de modo que agora o alvo prioritário são os estúdios e transmissores das estações de televisão e de rádio. Particularmente importantes de serem observados foram os esforços, às vezes sangrentos, de grupos de oposição em ocupar as estações de transmissão na Lituânia, Estônia e da própria Moscou no curso da dissolução da URSS, no início da década de 90 . Por causa da cobertura mais ampla, as estações de rádio têm tido importância para os rebeldes, como um prêmio revolucionário atraente, e podem até mesmo ser mais importantes do que a TV.

Quando estações de rádio caem em mãos erradas e são usadas para os propósitos errôneos, os resultados podem ser nefastos. Exemplo foi o massacre da população Tutsi em Ruanda, 1994, quando a estação RTLM incitou os Hutus a assassinar seus vizinhos Tutsi. Cees Hamelink diz que a RTLM (a estação de rádio/

72. RAMIREZ, Mina. Communication and social change: value implications. In: Media and politics in transition: cultural identify in the age of globalization. (Comunicação e mudança social: valores implicados. In: Mídia e políticas em transição: identidade cultural na era da globalização.) Netherlands: Acco, 1997. p. 47.

73. MCGUIRE, T. Will... op. cit. p. 13. 
TV Hutu) teve um papel de incitação e agravamento desse massacre, ao transmitir repetidamente mensagens nas quais os Tutsis eram xingados, ridicularizados e descritos como vis. A milícia Hutu era informada pela RTLM sobre onde os Tutsis - aos quais se referiam como baratas - estavam escondidos, para que fossem massacrados. A propaganda de ódio teve tanto sucesso que vizinhos, que haviam vivido em paz por muitos anos, foram mortos por pessoas que se consideravam amigas.

\section{Radiodifusão por minorias indígenas}

$O$ rádio e, em um grau um pouco menor, a televisão têm sido usados em esforços para fornecer programação apropriada, tanto no sentido cultural como linguístico, para povos de minorias indígenas em várias partes do mundo. Browne descreveu métodos dessa natureza na Nova Zelândia, Austrália e em diversas outras regiões do mundo. Ele observa, em especial, os problemas que os radiodifusores encontram quando há vários idiomas presentes em suas áreas de recepção. Dar atenção igual a todos pode ser impossível, mas ignorá-los pode ampliar as diferenças étnicas ${ }^{74}$.

Michael Keith discute o andamento do conceito nos Estados Unidos. O governo dos EUA reconhece 547 tribos, compondo um total de 2 milhões de pessoas, das quais cerca de metade vive em 300 reservas, em 33 estados. Até recentemente, poucos líderes tribais estavam interessados na idéia de estações de rádio patrocinadas pelas tribos. Mas muitos mudaram de idéia por volta de 1970 , possivelmente coincidindo com a maior disponibilidade de rádios transistorizados, que são mais resistentes e melhor adequados para operação por bateria e, portanto, às condições rurais. Um motivo mais forte foi o aumento da consciência, entre os líderes tribais, do poder que a mídia tem para ir ao encontro das necessidades de seus povos. As estações tribais são desejáveis à medida que estações comerciais controladas por brancos, próximas às reservas, de modo geral, davam pouca atenção aos interesses dos nativos, pois eles tinham relativamente pouco poder de compra. Keith ressalta que as estações sob o controle tribal ajudam a reconfirmar a identidade nativa e dão a eles a sensação de que o futuro está sob seu controle, em vez de estar sendo determinado pela comunidade branca ${ }^{75}$.

No início da década de 90 , cerca de 30 estações de tribos estavam no ar nos Estados Unidos, e mais seis estavam prestes a iniciar suas transmissões dentro de um período de um ano. Essas estações estavam concentradas nos estados com as maiores populações indígenas, como o Alasca, Arizona, Oklahoma, Novo México e Dakota do Sul. Apenas três se localizam ao leste do Rio Mississippi.

\section{Transmissões de propaganda}

Ambos os lados na Guerra Fria investiram pesadamente em transmissões de propaganda, tanto pelas ondas curtas como pelo rádio $\mathrm{AM}$ e, onde possível, pela televisão. $\mathrm{O}$ investimento incluía não apenas as transmissões próprias, mas também embaralhar as transmissões dos inimigos, o que exigia ter transmissores com pelo menos poder igual àqueles que estavam sendo embaralhados. Gareth Price ${ }^{76}$ cita uma estimativa que dá conta de que as ações para embaralhar transmissões estavam custando, para a União Soviética, 800 milhões de dólares por ano, no início da década de 80 . As redes nacionais - BBC, Voz da América, Rádio Moscou etc., envolvidas em transmissões internacionais, tinham ambas as funções: fazer propaganda clan-

\footnotetext{
74. BROWNE, Donald R. Electronic media and indigenous peoples: a voice of our own. (Mídia eletrônica e populações indígenas: nossa voz.) Ames: Iowa State University Press, 1996.

75. KEITH, Michael C. Signals in the air: Native broadcasting in America. (Sinais no ar: radiotransmissão nativa na América.) Westport, CT: Praeger (Greenwood), 1995.
} 
destina e também não-clandestina. Alguns radiodifusores estavam orientados para seus próprios povos, localizados em locais remotos, e esse foi o propósito inicial de estabelecer o $B B C$ World Service, mas outros - em especial as transmissões em idiomas estrangeiros - eram explicitamente para propaganda.

Outras estações, como a Rádio Free Europe (Rádio Europa Livre) e a RIAS (Radio in the American Sector of Berlin, ou Rádio no Setor Americano de Berlim), foram estabelecidas especificamente para transmissões com intenções políticas para regiões não alinhadas ao Ocidente. A União Soviética tinha, além da Rádio Moscou, a Rádio Peace and Progress (Rádio Paz e Progresso) para o mesmo propósito. A maioria das estações de propaganda branca, exceto pelas estações usadas para embaralhar os sinais, respeitava as regras internacionais e mantinha-se nas frequiências designadas. As violações ocorriam, nas áreas alvo, tão somente nos casos onde os radiodifusores queriam invadir as transmissões populares locais.

Um dos esforços americanos de propaganda de rádio mais controversos foi a Rádio Marti, transmitindo, a partir de 1985, abertamente para Cuba, como uma estação branca. Ela havia sido precedida pela Rádio Swan, estabelecida pela Agência Central de Inteligência (CIA) norte-americana, nas Ilhas Swan, em 1960, pouco depois da vitória comunista em Cuba. A Rádio Swan tinha originalmente como objetivo ser uma estação preta, mas as circunstâncias levaram-na a operar mais abertamente, sob a cobertura comercial.
Resumo: Artigo trata do rádio, em seus diversos aspectos, enquanto meio de comunicação de massa que se firmou na primeira metade deste século e tem passado por profundas transformações tecnológicas. Do percurso da válvula, ao transistor e ao sinal digital - inovação que vem sendo implantada em todo o mundo, tornando ainda mais ágil e de qualidadade as transmissões - o rádio esteve e está presente em diversificadas atividades da sociedade. Apesar de ser tratado com menor prestígio do que a televisão, ele tem alcançado ampla diversificação em sua freqüência, permitindo a veiculação de programação em $F M, A M$ e OM. $O$ autor destaca as diferentes características de regulamentação e de sua exploração na Europa, EUA e América Latina. Discute a conveniência de tê-lo como um serviço regulado pelo setor estatal e/ou público ou, então, pelo setor privado. Apresenta ainda aspectos do uso democrático desse meio de comunicação, que tem sido veículo de propaganda de forças conservadoras $(\mathrm{ClA})$ e revolucionárias (zapatistas), bem como de etnias que tentam preservar sua identidade.

Palavras-chave: rádio, tecnologia, regulamentação, democracia, serviço público
Abstract:The article deals with the radio, in its diverse aspects, as a means of mass communication which was established in the first half of this century and that has undergone great technological transformation. From the valve to the transistor, and to the digital signal - innovation that has been being implemented all over the World, making transmissions even more agile and of high quality the radio has been and still is present in the most diverse of society's activities. Although it has been given less prestige than TV has, the radio has reached a great diversification in its frequency, allowing for $F M, A M$ and $M W$ programming broadcasts. The author emphasizes the different regulation characteristics and its exploration in Europe, U.S.A., and in Latin America. It discusses the convenience of having it as a service that is regulated by the State and/or public sector or even by the private sector. It also presents aspects for the democratic use of this means of communication, that has been a propaganda vehicle used by conservative (CIA) and revolutionary (Zapatista) forces, as well as by ethnic groups trying to preserve their identities.

Key words: radio, technology regulation, democracy, public service 